\title{
BMJ Open A call for Applied Knowledge and Lived Interdisciplinarity in the medical care of depressed employees: a cross- sectional survey with German occupational physicians and psychotherapists
}

\author{
Lina Nassri, Isabell Schneider, Petra Maria Gaum, Jessica Lang
}

To cite: Nassri L, Schneider I, Gaum PM, et al. A call for Applied Knowledge and Lived Interdisciplinarity in the medical care of depressed employees: a cross-sectional survey with German occupational physicians and psychotherapists. BMJ Open 2018;8:e21786. doi:10.1136/ bmjopen-2018-021786

- Prepublication history for this paper is available online. To view these files please visit the journal online (http://dx.doi org/10.1136/bmjopen-2018021786).

Received 17 January 2018 Revised 14 June 2018 Accepted 3 July 2018

Check for updates

(C) Author(s) (or their employer(s)) 2018. Re-use permitted under CC BY-NC. No commercial re-use. See rights and permissions. Published by BMJ.

Institute for Occupational, Social and Environmental Medicine, RWTH Aachen University, Aachen, Germany

Correspondence to

Lina Nassri;

lina.nassri@rwth-aachen.de

\section{ABSTRACT}

Objectives To identify approaches for an effective patientcentred care of depressed employees, we investigated occupational physicians' (OPs) and psychotherapists' (PTs) knowledge about job stressors on the development of depression, application of this knowledge, interdisciplinary cooperation and perceived barriers.

Study design A cross-sectional online survey. Participants OPs (163; 48.5\% male) and PTs (69; 43.5\% male) providing complete data on the survey out of 257 OPs and 112 PTs who started the survey. There have been 458 (OPs) and 821 (PTs) initial clicks.

Methods Main outcome measures were the importance ratings of specific job stressors, the frequency of asking patients about those stressors, the need for interdisciplinary cooperation, as well as perceived barriers for cooperation. We performed multivariate analysis of variance, intraclass correlation coefficients (ICCS) and Spearman's rank-order correlations.

Results The achieved response rate for OPs was $56.1 \%$ and for PTs $13.6 \%$. Both disciplines agreed on the importance of job stressors regarding depression (ICC $=0.90 ; 95 \% \mathrm{Cl}: 0.54$ to 0.98 ), but both ranked these factors differently from the current state of research. As to knowledge application, OPs showed positive associations between the importance of job stressors and the frequency of asking employees about them (eg, job insecurity $\left.\left(r_{s}=0.20, p=0.005\right)\right)$ and PTs for social stressors (eg, interpersonal conflicts $\left(r_{s}=0.38\right.$, $\mathrm{p}=0.001)$ ). OPs (mean=3.41) reported a higher necessity of interdisciplinary cooperation than PTs (mean $=3.17$; $F(1,230)=7.02, p=0.009)$. Furthermore, cooperation was reported as difficult to implement. PTs perceived barriers (eg, time restriction) as more hindering (mean=3.2) than OPs (mean=2.8; $F(1,171)=8.16, p=0.005)$.

Conclusions Both disciplines are aware of the relevance of job stressors as risk factors for depression, but should be encouraged to ask employees more frequently about them. The need for interdisciplinary cooperation and possible barriers are discussed. It is crucial to emphasise the meaning of sufficient cooperation, since closing this gap for improving

\section{Strengths and limitations of this study}

Despite the relatively small sample size and self-selection of participants, respondents seem to be representative, since they report the occurrence of depression in their daily practice equivalently to the national prevalence rate.

- This is the first quantitative study illuminating the interdisciplinary cooperation between occupational physicians and psychotherapists regarding the care for the growing number of depressed employees.

- Identical questions were posed anonymously to big groups of occupational physicians and psychotherapists, thus the data are perfectly comparable.

patient-centred care especially for employees suffering from depression is necessary.

\section{INTRODUCTION}

Occupational physicians' (OPs) purpose is to preserve the work ability of employees, prevent acknowledged occupational diseases, carry out health precautions and support occupational rehabilitation and reintegration. ${ }^{1}$ They conduct pre-employment examinations, medical preventive check-ups and support risk assessment, which are their main source of information concerning the employees. ${ }^{2}$ Since in many industrialised nations the majority of the population is in the labour force, ${ }^{3}$ the working environment is the perfect place to take action against a widespread disease like depression. ${ }^{4}$ Currently, the number of sick leave days and early retirement due to psychiatric diseases such as depression is increasing. ${ }^{4}$ About $15 \%$ of all sick leave days are accounted to psychiatric disorders ${ }^{5}$ and the average sick leave 
of patients with a depressive episode is twice as high as sick leave in general, ${ }^{4}$ leading to enormous costs due to loss of production. ${ }^{5}$ The mean age onset for a depressive episode is between 25 and 30 years, ${ }^{6}$ implying that mostly the working population is affected by depression.

Recent studies showed a significant association between work-related stress and a higher risk for depression. ${ }^{7-13}$ Work-related stressors such as high job demand, low job control, low coworker or supervisor support can be even predictive for the development of psychiatric disorders. ${ }^{10}$ Even though the development of depression is seen as a holistic process including genetic, neurobiological, sociocultural, individual and work-related influences, ${ }^{14} 15$ job stressors are discussed to increase the risk to evolve a depression by $42 \%$ to $51 \%$ without including individual vulnerability. ${ }^{16}$ Although life stressors are also risk factors for depression ${ }^{1718}$ and OPs are regularly confronted with employees' general stress in life, ${ }^{19}$ we focus on work-related risk factors in this work, not only because work-related factors can be even weightier than personal and social factors ${ }^{20}$ but also because they play an important role in the return-to-work process after depressive episodes, ${ }^{21}$ where both OPs and PTs are involved. Since OPs have a key role for occupational health, it is crucial that they are aware of the importance of work-related stressors.

Besides the knowledge about work-related causes of depression, it is also relevant to apply this knowledge regularly in consulting employees or employers. A qualitative study reports a knowledge-behaviour gap in general practitioners (GPs) related to mental health (ie, autism $)^{22}$ because of structural barriers and knowledge deficits, for example. These two examples are important factors related to interdisciplinary cooperation.

OPs' task field does not only overlap with the field of GPs but also with psychotherapists (PTs), especially in the context of rehabilitation and occupational reintegration of employees with psychiatric disorders such as depression. The main interface between OPs and other disciplines (eg, PTs) is considered to be the informational exchange regarding job setting and specific stressors. ${ }^{23}$ After all, PTs also will benefit from cooperating with OPs by receiving objective information about patients' working conditions, since patients with psychiatric disorders tend to have an altered perception. ${ }^{24} 25$ Moreover, it has been shown that a cognitive-behavioural therapy carried out by PTs results in a faster return to work and financial advantages for the employer if direct and specific work-related interventions were undertaken. ${ }^{21}$ However, the PT's range of action is limited when it comes to the implementation of structural changes at work, since it is the OP's responsibility to advise the employer. ${ }^{26}$ To conclude, there is a need for interdisciplinarity.

But, according to several studies in the past years, interdisciplinary communication and cooperation between OPs with GPs and rehabilitation physicians have been proven to be insufficient and non-continuous, ${ }^{2327-30}$ even though sufficient interdisciplinarity has been shown to improve the outcome, that is, earlier return to work and high return-to-work ratio, reduced work disability duration and more sustainable reintegration. ${ }^{31-34}$ Still, there is a common awareness of OPs and GPs that an improvement of communication and cooperation is inevitable for a better patient-centred care. ${ }^{27}$ Besides that, recent studies have identified the main barriers to a sufficient cooperation on a regular basis such as schedule restrictions, low reachability or medical confidentiality and deficient or prejudiced knowledge of an OP's work field and responsibilities. ${ }^{23} 2735$ To the authors' knowledge, there are no studies of interdisciplinary cooperation and barriers between OPs and PTs, which would be necessary in order to contribute to a sustainable and effective medical care of depressed employees.

The present study's aim is to understand medical care of employees with work-related depression in the organisational setting:

1. Do OPs and PTs know work-related stressors and their influence on the development of depression?

2. Does their knowledge concerning work-related stressors influence their daily practice?

3. Do OPs and PTs cooperate and do they see a need for interdisciplinarity?

4. What are possible barriers for interdisciplinary cooperation?

\section{Part 1: Knowledge}

In Research Question 1.0 (RQ1.0), we investigate how OPs and PTs evaluate general and work-related conditions regarding the development of depression and whether their evaluations differ. Subsequently, we analyse whether OPs and PTs disagree on the relative importance of specific work-related factors regarding the development of depression (RQ1.1). RQ1.2 adheres to the question, whether the OPs' and PTs' evaluations of specific work-related factors differ from the current state of research.

\section{Part 2: Applied Knowledge}

After outlining the OPs' and PTs' knowledge of work-related factors and their relevance for developing depression (part 1), part 2 depicts the possible application of that knowledge. We assume that OPs and PTs ask employees more about specific work-related factors, which they evaluated more important concerning the development of depression. Specifically, Hypothesis 1 (H1) postulates a positive association between the relevance of specific work-related factors and the frequency of asking.

\section{Part 3: Need for Interdisciplinarity}

The working field of OPs and PTs overlaps prevailingly owing to employees with psychiatric disorders. The fact that depressed employees might aggravate perceived work-related stressors, ${ }^{24}{ }^{25}$ strengthens the meaning of objective informational exchange between OPs and PTs. Considering that OPs are already aware of the importance of a sufficient interdisciplinary cooperation and wish for improvement, ${ }^{27}$ we hypothesise that OPs see a greater 
necessity of interdisciplinary cooperation with PTs than PTs do (H2).

\section{Part 4: Lived Interdisciplinarity}

Finally, we explore whether the OPs and PTs perceived need of interdisciplinarity has consequences by pursuing the question, how often OPs are consulted by PTs because of occupational reintegration (RQ2.0). Also, we analyse whether OPs and PTs perceive barriers for interdisciplinary cooperation differently (RQ3.0).

\section{METHODS}

\section{Procedure}

We conducted an anonymous online questionnaire separately on OPs and PTs in Germany from May to November 2016. The OPs and PTs were approached via exclusive mailing lists of expert associations and social media.

\section{Patient and public involvement}

No patients were involved in this study. The research questions were developed based on previous studies about OPs, their experiences and practice as well as interdisciplinary cooperation with other disciplines (eg, GPs). Study participants will be provided with the results on request.

\section{Knowledge and Applied Knowledge}

To assess the relevance of general factors associated with the development of depression, respondents had to provide a percentage number regarding genetic, social, individual and work-related factors. Further, we referred to nine specific work-related factors, based on results from meta-analytic reviews ${ }^{7-13}$; these were effort-reward imbalance, high job demands, interpersonal conflicts including bullying, job insecurity, low decision latitude/job control, low social support from coworkers or supervisors, organisational injustice, role ambiguity and shift work. We asked the OPs and PTs how relevant they consider these work-related factors for the development of depression ( 1 = 'not important at all' to $4=$ 'very important'). We also assessed how often OPs and PTs ask their patients about specific work-related factors $(1=$ 'never' to $5=$ 'always' $)$. OPs and PTs who have stated in a preliminary question to have never worked with depressed employees did not receive the first two questions and were not considered in the data analyses of Knowledge and Applied Knowledge. Additionally, participants who provided ' $0 \%$ ' as a percentage number for work-related factors in the second question were also excluded from the subsequent questions of the Knowledge and Applied Knowledge Part.

\section{Need and barriers of cooperation}

Participants were asked how necessary they considered cooperation with PTs/OPs to be, especially with regard to employees with psychiatric disorders $(1=$ 'not necessary at all' to $4=$ 'absolutely necessary').

The question 'How often have you been actually consulted by PTs because of occupational reintegration and rehabilitation of employees with psychiatric disorders' $(1=$ 'never' to $5=$ 'always' $)$ was only posed to OPs. Furthermore, both were asked, why cooperation is difficult to implement in everyday working life and listed specific barriers that could be rated with a scale from $1=$ 'disagree' to $4=$ 'agree'. Barriers for insufficient cooperation were time restriction, lacking remuneration, data privacy regulations/medical confidentiality, deficient knowledge of the other discipline (eg, prejudices), medical care in reality, difficult approach to other disciplines and low reachability. These barriers were mainly derived from previous studies ${ }^{23}$ 27-29 predominantly dealing with cooperation between OPs and GPs.

\section{Data analysis}

All analyses were conducted with IBM SPSS Statistics Version 22. To answer RQ1.0, we performed a multivariate analysis of variance (MANOVA). For RQ1.1, we determined the intraclass correlation coefficient (ICC) between OPs and PTs regarding their evaluation of the nine specific work-related factors. To answer RQ1.2, ranking orders of OPs' and PTs' evaluated importance concerning work-related factors that were generated based on mean values. Respectively, we built a ranking order resembling the current state of research based on ORs reported in meta-analyses. We compared all three ranking orders descriptively. H1 was tested with Spearman's rank-order correlation, whereas $\mathrm{H} 2$ with a one-way analysis of variance. With regard to RQ2.0, a descriptive data analysis was performed, whereas we carried out a MANOVA to confirm RQ3.0 as well as determined the ICC. RQ3.0 referred to difficulties in interdisciplinary cooperation. Participants who did not see any difficulties were excluded. In all MANOVAs we used Bonferroni correction to balance the multiple comparisons problem.

\section{RESULTS}

\section{Study population and participation}

Initially, out of 458 clicks, 257 OPs started the survey and 163 reached the final page. As to the PTs, out of 821 clicks, 112 PTs participated and only 69 reached the final page. Only finalised questionnaires were included. It was not obligatory to answer each question. The final sample consisted of 232 participants (163 OPs and $69 \mathrm{PTs}$ ). All in all, the total response rate was $56.1 \%$ for OPs and $13.6 \%$ for PTs. Further details are provided in table 1.

\section{Part 1: Knowledge}

Altogether, only one OP and one PT stated to have never had a depressed employee as a patient, whereas three more OPs provided $0 \%$ for work-related factors and were excluded from subsequent questions.

Regarding RQ1.0, there was no significant difference in general, individual, sociocultural and work-related conditions $(\mathrm{F}(3,224)=0.04, \mathrm{p}=0.989$; Wilk's lambda $(\Lambda)=1.00$, partial eta squared $\left.\left(\eta^{2}\right)=0.00\right)$. For further details, see table 2. OPs and PTs did not evaluate general and 


\begin{tabular}{|c|c|c|}
\hline \multirow[b]{2}{*}{ Physicians } & \multirow{2}{*}{$\begin{array}{l}\text { Occupational } \\
\text { physicians } \\
\mathrm{n}(\%) \\
\end{array}$} & \multirow{2}{*}{$\begin{array}{l}\text { Psychotherapists } \\
\mathrm{n}(\%)\end{array}$} \\
\hline & & \\
\hline Participants & $163(70.26)^{\star}$ & $69(29.74)^{\star}$ \\
\hline $\begin{array}{l}\text { Age (in years; mean } \\
\text { (SD)) }\end{array}$ & $51.90(8.35)$ & $47.10(10.03)$ \\
\hline \multicolumn{3}{|l|}{ Sex } \\
\hline Male & $79(48.50)$ & $30(43.50)$ \\
\hline Female & $84(51.50)$ & $39(56.50)$ \\
\hline \multicolumn{3}{|l|}{ Work experience (years) } \\
\hline $1-10$ & $48(30.19)$ & $24(34.78)$ \\
\hline $11-20$ & 56 (35.22) & $17(24.64)$ \\
\hline$\geq 21$ & 55 (34.59) & $28(40.58)$ \\
\hline $\begin{array}{l}\text { Relative frequency of } \\
\text { depressed patients, } \dagger \\
\text { mean (SD) }\end{array}$ & $11.51(11.56)$ & $25.04(14.90)$ \\
\hline
\end{tabular}

Not all questions were obligatory to answer, thus the total might not always reach 163 or 69 .

${ }^{*}$ Referring to the whole study population $(n=232)$.

†Mean of estimated prevalence of depressed employees in the companies that the physician is responsible for/in treatment at psychotherapists.

work-related conditions differently regarding the development of depression, thus RQ1.0 could not be confirmed.

Furthermore, OPs and PTs did not disagree on the relative importance of specific work-related factors (RQ1.1). A significant high degree of consistency ( $\mathrm{ICC}=0.90$; 95\% CI: 0.54 to 0.98 ) was found between the mean values of OPs and PTs $(\mathrm{F}(8,8)=9.57, \mathrm{p}=0.002)$. RQ1.1 could be confirmed.

In matters of RQ1.2, descriptively both groups ranked specific work-related factors slightly different from the current state of research. OPs and PTs evaluated the factors 'interpersonal conflicts, bullying', 'low social support from supervisors and coworker' and 'low decision latitude/lowjob control' as more important. 'Job insecurity' was evaluated as more important by PTs and equal to the current state of research by OPs (table 3). The factors 'role ambiguity', 'organisational injustice', 'effort-reward imbalance' and 'high job demands' were ranked lower by OPs and PTs than in the current state of research. The biggest differences were observed for 'low social support from supervisors and coworkers', 'low decision latitude/low job control' as well as 'role ambiguity'. Accordingly, RQ1.2 could only partially be confirmed.

\section{Part 2: Applied Knowledge}

The aim of $\mathrm{H} 1$ was to determine the association between the evaluated relevance of specific work-related factors and the frequency of asking employees about those specific factors. For OPs, there were small to medium positive correlations between the relevance of 'low social support from supervisors' and the frequency of asking about that specific stressor $\left(r_{s}=0.24, p=0.001\right)$. The same applied to 'job insecurity' $\left(r_{s}=0.20, p=0.005\right)$ and 'low decision latitude/low job control' $\left(r_{s}=0.29, p<0.001\right)$, whereas for 'interpersonal conflicts, bullying' and 'low social support from coworker', the correlation was not significant (table 4). As to PTs, three out of five factors showed a medium positive, significant correlation, namely 'interpersonal conflicts, bullying' $\left(\mathrm{r}_{\mathrm{s}}=0.38, \mathrm{p}=0.001\right)$, 'low social support from coworkers' $\left(\mathrm{r}_{\mathrm{s}}=0.29, \mathrm{p}=0.008\right)$ and 'low social support from supervisors' $\left(r_{s}=0.37, p=0.001\right)$. For 'job insecurity' $\left(\mathrm{r}_{\mathrm{s}}=0.21, \mathrm{p}=0.043\right)$, a small positive correlation has been shown.

Hence, $\mathrm{H} 1$ can be almost fully confirmed. There are positive associations between the evaluated relevance of specific work-related factors and the frequency of asking about them for both groups.

\section{Part 3: Need for Interdisciplinarity}

In H2, we investigated differences between OPs' (n=163) and PTs' $(n=69)$ perceived necessity of interdisciplinary cooperation. There was a significant difference between OPs and PTs $(\mathrm{F}(1,230)=7.02, \mathrm{p}=0.009)$. OPs report a higher necessity for interdisciplinary cooperation (mean=3.4; $\mathrm{SD}=0.6$ ) than PTs (mean=3.2; $\mathrm{SD}=0.6)$. H2 could be fully confirmed.

\section{Part 4: Lived Interdisciplinarity}

According to RQ2, $50.6 \%$ of the OPs $(n=162)$ stated that they were 'never' consulted by PTs and $36.4 \%$ reported they were 'rarely' consulted. Only $8.6 \%$ said that they are contacted 'sometimes', $3.7 \%$ 'often' and $0.6 \%$ 'always' (mean=1.7, $\mathrm{SD}=0.8$ ). OPs were barely ever consulted by PTs in the context of rehabilitation and occupational reintegration of employees with psychiatric disorders.

Table 2 Perceived importance of general conditions for the development of depression in per cent

\begin{tabular}{llll} 
& Between-subjects effects & $\begin{array}{l}\text { Occupational physicians, } \\
\text { mean (SD) }\end{array}$ & $\begin{array}{l}\text { Psychotherapists, } \\
\text { mean (SD) }\end{array}$ \\
\hline Genetic conditions & $F(1,226)=0.00, p=0.996$ & $25.1(15.5)$ & $25.1(10.9)$ \\
Individual conditions & $F(1,226)=0.11, p=0.741$ & $25.0(10.4)$ & $25.4(7.4)$ \\
Sociocultural conditions & $F(1,226)=0.03, p=0.870$ & $29.4(11.1)$ & $29.1(12.5)$ \\
Work-related conditions & $F(1,226)=0.02, p=0.903$ & $20.6(10.5)$ & $20.4(8.8)$ \\
& & $100 \%$ & $100 \%$ \\
\hline
\end{tabular}

Pvalue (significance), $n=228$. 
Table 3 Perceived importance of specific work-related factors for the development of depression compared with current state of research

\begin{tabular}{|c|c|c|}
\hline $\begin{array}{l}\text { Ranking order occupational } \\
\text { physicians }(n=159)\end{array}$ & $\begin{array}{l}\text { Ranking order current state of research } \\
\text { (OR) }\end{array}$ & Ranking order psychotherapists $(n=68)$ \\
\hline$\uparrow$ Interpersonal conflict, bullying & 1. Role ambiguity $(2.86)^{12}$ & $\uparrow$ Interpersonal conflicts, bullying \\
\hline$\downarrow$ Role ambiguity & $\begin{array}{l}\text { 3. Organisational injustice: relational, } \\
\text { procedural }(1.51,1.78)^{10}\end{array}$ & $\uparrow$ Job insecurity \\
\hline $\begin{array}{l}\downarrow \text { Organisational injustice: relational, } \\
\text { procedural }\end{array}$ & 5. Shift work $(1.43)^{11}$ & $\uparrow$ Low decision latitude/job control \\
\hline$\leftrightarrow$ Job insecurity & 6. Job insecurity $(1.29)^{13}$ & $\downarrow$ Role ambiguity \\
\hline$\downarrow$ Effort-reward imbalance & 7. High job demands $(1.14)^{7}$ & $\downarrow$ Effort-reward imbalance \\
\hline
\end{tabular}

Arrows indicate the relative position in comparison to the current state of research.

Through a preliminary analysis for RQ3.0, $16.0 \%$ $(n=26)$ of the OPs and $24.6 \% \quad(n=16)$ of the PTs were excluded, because they perceived interdisciplinary cooperation easily to implement, RQ3.0 deals with the perception of barriers and difficulties to sufficient interdisciplinary cooperation. A significant multivariate main effect between OPs and PTs was found $(\mathrm{F}(7,165)=3.90$, $\mathrm{p}=0.001$; Wilk's $\Lambda=0.86$, partial $\left.\eta^{2}=0.14\right)$. OPs and PTs evaluate the barriers 'time restriction', 'lacking remuneration', 'deficient knowledge of the other discipline (eg, prejudices)', 'difficult approach to other disciplines' differently. PTs rated all of those barriers as more hindering than OPs (see table 5). There was a consent concerning 'data privacy regulations/medical confidentiality', 'medical care in reality', 'low reachability of PTs/ OPs'. The described differences only applied to the evaluation of OPs and PTs regarding the relative relevance of those barriers in hindering cooperation, not the ranking of the relevance of those barriers within each group. As to the ranking order between the groups, there has been a high degree of significant consistency ( $\mathrm{ICC}=0.78$; $95 \% \mathrm{CI}$ : -0.31 to $0.96 ; \mathrm{F}(6,6)=4.44, \mathrm{p}=0.046)$.

\section{DISCUSSION}

The aim of this study was to specify the interdisciplinary cooperation between OPs and PTs in order to improve medical care of employees with work-related depression.

In the first part (ie, Knowledge), the results show that both disciplines have an equivalent level of knowledge concerning general conditions that increase the risk to develop a depression. They agree on the relevance of all general conditions, even though they rated the work-related conditions as least important with only $20 \%$ compared with genetic, individual and sociocultural conditions. Nevertheless, developing a psychiatric disorder such as depression derives from a holistic, biopsychosocial process ${ }^{14}$ and return-to-work interventions

Table 4 Spearman's rank-correlation coefficients $\left(r_{s}\right)$ for the associations of the evaluated importance of specific work-related factors and the frequency of asking about each specific factor

\begin{tabular}{|c|c|c|c|c|}
\hline & \multicolumn{4}{|c|}{ Frequency of asking about the same specific factor evaluated } \\
\hline & \multicolumn{2}{|c|}{ Occupational physicians $(n=154)$} & \multicolumn{2}{|c|}{ Psychotherapists $(n=68)$} \\
\hline & $\mathbf{r}_{\mathrm{s}}$ & P value & $\mathbf{r}_{\mathrm{s}}$ & $\mathbf{P}$ value \\
\hline Interpersonal conflicts, bullying & 0.13 & 0.055 & 0.38 & 0.001 \\
\hline Low social support from coworker & 0.10 & 0.119 & 0.29 & 0.008 \\
\hline Job insecurity & 0.20 & 0.005 & 0.21 & 0.043 \\
\hline Low decision latitude & 0.29 & $<0.001$ & 0.17 & 0.08 \\
\hline
\end{tabular}

Significant results are in bold. 
Table 5 Perceived barriers for interdisciplinary cooperation with PTs/OPs (MANOVA)

\begin{tabular}{|c|c|c|c|}
\hline Barriers to cooperation & Between-subjects effects & $\begin{array}{l}\text { OPs, } \\
\text { mean (SD) }\end{array}$ & $\begin{array}{l}\text { PTs, } \\
\text { mean (SD) }\end{array}$ \\
\hline Time restriction & $F(1,171)=8.16, p=0.005, \eta^{2}=0.05$ & $2.8(1.0)$ & $3.2(0.7)$ \\
\hline Data privacy regulations/medical confidentiality & $F(1,171)=0.99, p=0.321, \eta^{2}=0.01$ & $3.0(1.0)$ & $3.1(0.9)$ \\
\hline $\begin{array}{l}\text { Deficient knowledge of the other discipline (eg, } \\
\text { prejudices) }\end{array}$ & $F(1,171)=5.76, p<0.001, \eta^{2}=0.08$ & $2.5(1.0)$ & $3.1(1.0)$ \\
\hline Difficult approach to other disciplines & $F(1,171)=4.96, p=0.027, \eta^{2}=0.03$ & $2.8(1.0)$ & $3.1(0.8)$ \\
\hline Low reachability of OPs/PTs & $F(1,171)=0.70, p=0.406, \eta^{2}=0.00$ & $3.5(0.7)$ & $3.4(0.6)$ \\
\hline
\end{tabular}

Significant results are in bold.

$n=173$ (122 OPs; 51 PTs), p value (significance), $\eta^{2}=$ eta squared (effect size).

MANOVA, multivariate analysis of variance; OPs, occupational physicians; PTs, psychotherapists.

should address all the levels of the biopsychosocial model. ${ }^{36}$ Besides that, genetic and sociocultural preconditions cannot be as easily influenced as individual or work-related conditions. ${ }^{15}$ Thus, specific work-related risk factors for developing a depression were considered. OPs and PTs completely agree on the relevance of specific work-related stressors. In contrast to this agreement, the evaluation of both disciplines differs from the current state of research. Both groups emphasise the importance of occupational stressors in the social domain (eg, 'interpersonal conflicts, bullying' or 'low social support') more, whereas stressors in the organisational/structural domain (eg, 'role ambiguity', 'organisational injustice' or 'effort-reward Imbalance') are underestimated. The discrepancy between the current state of research and the participants' evaluation concerning 'interpersonal conflicts, bullying' is negligible because it differs only in one rank order position, whereas 'low social support' is ranked six levels higher than in literature. In literature, there are inconclusive findings regarding the effect of social support. In fact, prior research reports associations of social support with detrimental health outcomes. ${ }^{37}$ Probably, OPs and PTs do not reflect social support that differentiated in everyday working life. In contrast, 'role ambiguity' was underestimated, even though according to theoretical considerations the presence of role ambiguity is inevitably a stressor, ${ }^{38}$ since individual's coping mechanisms regarding this organisationally determined stressor are limited. ${ }^{38-40}$ Thus, role ambiguity can be seen as a more adverse stressor in comparison to other stressors such as job insecurity for instance, which can function as a motivator. ${ }^{38}$ This illustrates that even though the knowledge of our study population is mainly in line with prior research, there is still a need for further educational training and a consequent application in everyday practice.

Findings from the third and the fourth study part (Need for Interdisciplinarity and Lived Interdisciplinarity) confirm the assumption that OPs see a higher necessity for interdisciplinary cooperation than PTs, which corresponds to past research. ${ }^{27}$ In fact, half of the OPs state that they have never been consulted by PTs, which emphasises the expressed need by OPs for cooperation in part three. A bias due to social desirability ${ }^{41}$ cannot be excluded. However, we have tried to minimise the potential for bias by conducting an anonymous online survey. ${ }^{42}$ The obvious lack of cooperation results from diverse obstacles as over three-quarters of OPs and PTs find functioning interdisciplinary collaboration to be difficult to implement in everyday working life. Specifically, PTs perceive the majority of the barriers as stronger hindrance factors for cooperation, especially regarding time restriction and deficient knowledge of the other discipline. Particularly, the stronger perception of barriers by PTs might be an explanation for the lower rated necessity for cooperation, since the perception of an obstacle might have an impact on the actual behaviour. ${ }^{43}$

\section{Strengths and limitations}

Strengths of our study are that the groups consisted of representative and heterogenic participants from all over Germany as well as that it was of quantitative nature and thus enabled not only the identification of barriers but also their weighting. Both groups were rather big and despite of unequal numbers appropriately comparable. One important difference between OPs and PTs is their relationship with their 'clients'. Other than in the therapeutic setting with patients and their selected therapist, in the occupational setting employees may tend to withhold relevant health-related data from the company-selected OP. $^{28}$ The fact that the observed lifetime prevalence of depression is $11.6 \%{ }^{44}$ and is almost identical with the OPs' estimation of the percentage of their employees with depression strengthens the validity of our study.

Since our survey is a cross-sectional study, a development or personal change in the OPs' or PTs' point of view cannot be directly ascertained. Another limitation is that there might be a response bias so that only OPs and PTs who are confronted with insufficient cooperation and are aware of its relevance might have participated. 
Surely, the found barriers to interdisciplinary cooperation between OPs and PTs also result from the country-specific healthcare system the sample is derived from and thus not generalisable to other social and healthcare systems.

\section{Implications/further research}

In 2013, the German Occupational Safety and Health Act has been adjusted by focusing the requirement to explicitly include work-related mental psychosocial hazards in the risk assessment ( $\$ 5$ Section 3 ArbSchG). Due to sufficient knowledge regarding the influence of psychosocial stressors on depression, it seems that a reversal particularly concerning OPs has taken place, namely by shifting the sole focus on occupational risks to a more holistic approach which also comprises health and workplace surveillance. ${ }^{45}$

In addition, our study clarifies that even though OPs and PTs are rather sensitised to work-related stressors and their influence on depression, there is still a need for clarification of the role of certain work-related stressors, which seem to be neglected. Moreover, it is suggested that OPs and PTs should be encouraged to ask employees more frequently about certain work-related stressors in order to be able to prevent a significant increase of work-related stress and thus obviate the development of depression. Depression is the most common cause of sick leave, and improving cooperation between OPs and PTs may appear to be a promising intervention to prevent depression and other psychiatric disorders (eg, anxiety disorders or substance abuse). Interpersonal and organisational obstacles are easier to diminish than structural obstacles. ${ }^{23}$ In interpersonal and organisational obstacles, the involved parties themselves can take action, whereas structural obstacles are more complex and require the involvement of several stakeholders. Suggested solutions are for instance creating financial incentives, promoting cooperation and more education about OPs working field in order to reduce prejudices, technological solutions in order to facilitate informational exchange via encrypted emails and tighter involvement of OPs in the process of occupational reintegration as well as simplifying bureaucratic requirements for rehabilitation. ${ }^{23} 2728$

This work shows that not only the legal framework has to be adjusted to establish cooperation but also training, education and information of OPs, PTs and also employers and employees has to be conducted. In the training of physicians and PTs, it is crucial to emphasise the meaning of sufficient cooperation and communication between OPs and PTs in order to create mutual understanding and reduce barriers. Based on previous qualitative studies, which identified interdisciplinary barriers, the present quantitative study actually weighted these barriers, allowing to tackle greater and mutual obstacles, first. Further research should focus on the reduction of specific barriers to reduce the knowledge-behaviour gaps and strengthen the interdisciplinary cooperation.

\section{CONCLUSION}

In this study, we found small to medium associations between Knowledge and Applied Knowledge in OPs and PTs reflecting the knowledge-behaviour gap described in past research. ${ }^{22}$ Interdisciplinary cooperation is an opportunity to close this gap. This study gives hints that even though the Need for Interdisciplinarity is present, barriers are considered to be high. Nevertheless, there are still many gaps in research regarding the interfaces between OPs and PTs that have to be explored for providing an optimal healthcare of depressed employees in the organisational setting.

Acknowledgements The authors thank ArbMedNet (mailing list of the Institute and Outpatient Clinic for Occupational, Social and Environmental Medicine, Clinical Centre of the Ludwig Maximilian University Munich, Germany), DGAUM (Deutsche Gesellschaft für Arbeitsmedizin und Umweltmedizin), DPTV (Deutsche Psychotherapeuten Vereinigung) and VDBW (Verband Deutscher Betriebs- und Werkärzte e.V.) for approving this dissertation project by sharing the link to our survey through their mailing lists. We also thank Mourad Bouayad for his assistance with data collection (PTs).

Contributors The study concept and design was framed by LN, IS and JL. The questionnaire was developed by LN, IS, PMG and JL. LN performed the programming of the online questionnaire, data acquisition, created the tables and drafted the manuscript. LN and PMG conducted the statistical data analysis supported by IS and JL. JL gave professional expertise in occupational physician and psychotherapist practice, and also supervised the study. All authors read and approved the final manuscript.

Funding The authors have not declared a specific grant for this research from any funding agency in the public, commercial or not-for-profit sectors.

Competing interests None declared.

Patient consent Not required.

Ethics approval Ethics approval for the anonymous survey was not necessary since no health-related patient data were collected.

Provenance and peer review Not commissioned; externally peer reviewed.

Data sharing statement The datasets analysed during the current study are not publicly available. In the agreements of the study, participant-related raw data are not allowed to be shared, but anonymised data of the scales are available from the corresponding author on reasonable request.

Open access This is an open access article distributed in accordance with the Creative Commons Attribution Non Commercial (CC BY-NC 4.0) license, which permits others to distribute, remix, adapt, build upon this work non-commercially, and license their derivative works on different terms, provided the original work is properly cited, appropriate credit is given, any changes made indicated, and the use is non-commercial. See: http://creativecommons.org/licenses/by-nc/4.0/.

\section{REFERENCES}

1. Andrea $\mathrm{H}$, Beurskens AJ, Metsemakers JF, et al. Health problems and psychosocial work environment as predictors of long term sickness absence in employees who visited the occupational physician and/or general practitioner in relation to work: a prospective study. Occup Environ Med 2003;60:295-300.

2. Federal Ministry of Labour and Social Affairs [Bundesministerium für Arbeit und Soziales]. Occupational Medicine. Mental Health at Work - Occupational Recommendation [Arbeitsmedizin. Psychische Gesundheit im Betrieb - Arbeitsmedizinische Empfehlung]. Bonn, Germany: Hausdruckerei BMAS 2016. http://www.bmas.de/ SharedDocs/Downloads/DE/PDF-Publikationen/a450-psychischegesundheit-im-betrieb.pdf?_blob=publicationFile (accessed 25 Aug 2017).

3. The World Bank. Labor force participation rate, total (\% of total population ages 15+). https://data.worldbank.org/indicator/SL.TLF. CACT.ZS?name_desc=false (access 27 Nov 2017).

4. Robert-Koch-Institut. Health in Germany - Federal health monitoring jointly supported by RKI and Destatis [Gesundheit in Deutschland Gesundheitsberichterstattung des Bundes gemeinsam getragen von 
RKI und Destatis]. Berlin, Germany: Heenemann Printing Press, 2015. (accessed 30 Aug 2017)

5. Federal Institute for Occupational Safety and Health [Bundesagentur für Arbeitsschutz und Arbeitsmedizin]. Economic costs due to disability 2014 [Volkswirtschaftliche Kosten durch Arbeitsunfähigkeit 2014]. Dortmund, Germany: 2016. https://www.baua.de/DE/ Themen/Arbeitswelt-und-Arbeitsschutz-im-Wandel/Arbeitsweltb erichterstattung/Kosten-der-AU/pdf/Kosten-2014.pdf?_blob= publicationFile\&v=2 (accessed 21 Aug 2017).

6. Wittchen HU, Jacobi F, Klose M, et al. Health monitoring of the federal government Depressive illnesses [Heft 51 Gesundheitsberichterstattung des Bundes Depressive Erkrankungen]. Federal health monitoring jointly supported by Robert Koch Institut and Destatis. Berlin, Germany: Heenemann Printing Press, 2010. (accessed 25 Aug 2017)

7. Stuke H, Bermpohl F. [Which working conditions promote the development of depressive disorders?]. Psychiatr Prax 2016;43:245-52.

8. Theorell T, Hammarström A, Aronsson G, et al. A systematic review including meta-analysis of work environment and depressive symptoms. BMC Public Health 2015;15:738.

9. Rugulies R, Aust B, Madsen IE. Effort-reward imbalance at work and risk of depressive disorders. A systematic review and metaanalysis of prospective cohort studies. Scand J Work Environ Health 2017; 43:294-306.

10. Nieuwenhuijsen K, Bruinvels D, Frings-Dresen M. Psychosocial work environment and stress-related disorders, a systematic review. Occup Med 2010;60:277-86.

11. Lee A, Myung SK, Cho JJ, et al. Night Shift Work and Risk of Depression: meta-analysis of Observational Studies. J Korean Med Sci 2017;32:1091-6.

12. Schmidt $\mathrm{S}$, Roesler $\mathrm{U}$, Kusserow $\mathrm{T}$, et al. Uncertainty in the workplace: examining role ambiguity and role conflict, and their link to depression-a meta-analysis. European Journal of Work and Organizational Psychology 2014;23:91-106.

13. Kim TJ, von dem Knesebeck O. Perceived job insecurity, unemployment and depressive symptoms: a systematic review and meta-analysis of prospective observational studies. Int Arch Occup Environ Health 2016;89:561-73.

14. Cattapan-Ludewig K, Seifritz E. [Aetiology of depressive disorders-the biopsychosocial model]. Ther Umsch 2010;67:566-70.

15. Angerer P, Gündel H, Siegrist K. Stress: psychosocial work load and risks for cardiovascular disease and depression]. Dtsch Med Wochenschr 2014;139:1314-9.

16. Siegrist J, Lunau T, Wahrendorf M, et al. Depressive symptoms and psychosocial stress at work among older employees in three continents. Global Health 2012;8:27.

17. Tennant $C$. Life events, stress and depression: a review of recent findings. Aust N Z J Psychiatry 2002;36:173-82.

18. Hammen C. Cognitive, life stress, and interpersonal approaches to a developmental psychopathology model of depression. Dev Psychopathol 1992;4:189-206.

19. Magnavita N, Capitanelli I, Garbarino S, et al. Work-related stress as a cardiovascular risk factor in police officers: a systematic review of evidence. Int Arch Occup Environ Health 2018:1-13.

20. Lowe GS, Northcott HC. The impact of working conditions, social roles, and personal characteristics on gender differences in distress. Work Occup 1988;15:55-77.

21. Lagerveld SE, Blonk RW, Brenninkmeijer V, et al. Workfocused treatment of common mental disorders and return to work: a comparative outcome study. J Occup Health Psychol 2012;17:220-34.

22. Kennedy T, Regehr G, Rosenfield J, et al. Exploring the gap between knowledge and behavior: a qualitative study of clinician action following an educational intervention. Acad Med 2004;79:386-93.

23. Stratil JM, Rieger MA, Völter-Mahlknecht S. Cooperation between general practitioners, occupational health physicians, and rehabilitation physicians in Germany: what are problems and barriers to cooperation? A qualitative study. Int Arch Occup Environ Health 2017;90:481-90.
24. Szily E, Kéri S. Anomalous subjective experience and psychosis risk in young depressed patients. Psychopathology 2009;42:229-35.

25. de Lange AH, Taris TW, Kompier MA, et al. Different mechanisms to explain the reversed effects of mental health on work characteristics. Scand J Work Environ Health 2005;31:3-14.

26. Preiser $\mathrm{C}$, Rothermund E, Wittich A, et al. Psychosomatic consultation in the workplace: opportunities and limitations of the services offered--results of a qualitative study. Int Arch Occup Environ Health 2016;89:599-608.

27. Buijs P, van Amstel R, van Dijk F. Dutch occupational physicians and general practitioners wish to improve cooperation. Occup Environ Med 1999;56:709-13.

28. Stratil J, Rieger MA, Voelter-Mahlknecht S. Optimizing cooperation between general practitioners, occupational health and rehabilitation physicians in Germany: a qualitative study. Int Arch Occup Environ Health 2017;90:809-21.

29. Moßhammer D, Michaelis M, Mehne J, et al. General practitioners' and occupational health physicians' views on their cooperation: a cross-sectional postal survey. Int Arch Occup Environ Health 2016;89:449-59.

30. Monika S, Ristel N, Rebe T, et al. [Schnittstellenmanagement in der JobReha -Notwendigkeit einer verbesserten Zusammenarbeit zwischen Betriebs-und Rehabilitationsärzten]. Zentralblatt für Arbeitsmedizin, Arbeitsschutz und Ergonomie 2008;58:216-8.

31. Schwarze M, Spallek M, Korallus C, et al. Advantages of the JobReha discharge letter: an instrument for improving the communication interface in occupational rehabilitation. Int Arch Occup Environ Health 2013;86:699-708.

32. Franche RL, Cullen K, Clarke J, et al. The Institute for Work and Health (IWH) Workplace based RTW Intervention Literature Review Research Team: workplace based return-to-work interventions: a systematic review of the quantitative literature. J Occup Rehabil 2005;15:607-31.

33. Haase I, Riedl G, Birkholz LB, et al. Verzahnung von medizinischer Rehabilitation und beruflicher Reintegration]. Arbeitsmedizin Sozialmedizin Umweltmedizin 2002;37:331-5.

34. Weiler SW, Foeh KP, van Mark A, et al. Outpatient rehabilitation of workers with musculoskeletal disorders using structured workplace description. Int Arch Occup Environ Health 2009;82:427-34.

35. Moßhammer D, Natanzon I, Manske I, et al. [Deficiencies and barriers of the cooperation between German general practitioners and occupational health physicians? A qualitative content analysis of focus groups]. Z Evid Fortbild Qual Gesundhwes 2012;106:639-48.

36. Engel GL. The need for a new medical model: a challenge for biomedicine. Science 1977;196:129-36.

37. Elfering A, Semmer NK, Schade V, et al. Supportive colleague, unsupportive supervisor: the role of provider-specific constellations of social support at work in the development of low back pain. $J$ Occup Health Psychol 2002;7:130-40.

38. Gilboa S, Shirom A, Fried Y, et al. A meta-analysis of work demand stressors and job performance: examining main and moderating effects. Pers Psychol 2008;61:227-71.

39. King LA, King DW. Role conflict and role ambiguity: a critical assessment of construct validity. Psychol Bull 1990;107:48-64.

40. Kahn RL, Wolfe DM, Quinn RP, et al. Organizational stress: studies in role conflict and role ambiguity. New York: Wiley, 1964.

41. Edwards AL. The social desirability variable in personality assessment and research. New York, NY: Dryden Press, 1957.

42. Joinson A. Social desirability, anonymity, and Internet-based questionnaires. Behav Res Methods Instrum Comput 1999;31:433-8.

43. Aizen I. Perceived behavioral control, self-efficacy, locus of control, and the theory of planned behavior. J Appl Soc Psychol 2002;32:665-83.

44. Busch MA, Maske UE, Ryl L, et al. [Prevalence of depressive symptoms and diagnosed depression among adults in Germany: results of the German Health Interview and Examination Survey for Adults (DEGS1)]. Bundesgesundheitsblatt Gesundheitsforschung Gesundheitsschutz 2013;56:733-9.

45. Vanhoorne MN, Vanachter OV, De Ridder MP. Occupational health care for the 21st century: from health at work to workers' health. Int $J$ Occup Environ Health 2006;12:278-85. 